\title{
Fast Commutation of DC Current into a Capacitor Using Moving Contacts
}

\author{
Dragan Jovcic, Senior Member, IEEE
}

\begin{abstract}
The article describes a method of fast commutation of DC current into a capacitor. Theoretical study is provided which enables evaluation of commutating DC current for the given contact velocity, capacitance and dielectric strength. It is concluded that a non-zero contact velocity at separation is required, and a corresponding switch design is proposed.

Experimental results on a laboratory set up illustrate successful DC current commutation up to $400 \mathrm{~A}$, with voltages rising to 1.3 kV. Further experiments demonstrate that parasitic parameters reduce the magnitude of the current that can be commutated.

A detailed non-linear PSCAD model and a linear model for the parasitic circuit are presented to enable prediction of the success of commutation. The model accuracy is confirmed with experimental tests.

The DC current commutation in the proposed method occurs 5$10 \mu$ s after the contact separation, which is much faster than with other methods employing moving contacts. A further benefit of the extremely short arcing is elimination of thermal issues on contacts, and possible simplified design of the mechanical switch.
\end{abstract}

Index Terms-- DC switchgear, HVDC protection, DC Circuit Breakers.

\section{INTRODUCTION}

$\mathrm{T}$ There has been renewed interest in DC circuits recently, because of the growing application of DC in transmission (e.g. HVDC and DC grids [1]) and distribution/collection systems. At low DC voltages (say below $1 \mathrm{kV}$ ) the arc voltage is comparable with system voltage and no commutation is usually required. At higher voltages, DC current commutation is required in all DC CB (Circuit Breakers) technologies [2],[3], and sometimes multiple commutations are needed. Solid state switches represent an elegant solution to interrupt DC current without any arcing and to provide adequate counter-voltage to commutate DC current into another circuit of practically any voltage magnitude [4]-[7]. Semiconductors are used for this purpose with all converters but if only occasional commutation is required (like with DC CBs), then the cost, losses and size of semiconductor valves are difficult to justify.

When moving contacts (mechanical switches) are used for DC commutation, arcing becomes inevitable. In passive DC CBs [8], [9] electrode separation creates arc with increasing voltage as the electrodes move apart. Increasing arc voltage creates equivalent negative resistance and it may take $20-50 \mathrm{~ms}$ for the growing oscillations to cause current zero crossing and interruption of arc. The latest DC CBs based on moving contacts (active or current injection DC CBs) employ precharged capacitor which shortens the arcing time to $8-10 \mathrm{~ms}$
[10]. The arcing time in the range of tens of ms coupled with the high recovery voltages (over $100 \mathrm{kV}$ ) in these commutating circuits, lead to high energy dissipation and require special switches with arcing chambers and heavy electrodes. The high recovery voltages are result of insertion of surge arresters necessary to provide counter voltage in faulted DC circuit.

The arcing across a mechanical switch can be shorter if a semiconductor is placed in parallel [11], however semiconductor valve should be rated for full DC voltage.

The commutation of large DC currents between two DC busses in future DC substations has been extensively analyzed recently [12]. In this case DC CB are not necessary and DC disconnectors would be sufficient since recovery voltage is low (below $100 \mathrm{~V}$ ) and load currents are moderate (1-2 kA). However, arcing is also expected in the time frame of $10 \mathrm{~ms}$.

The commutation of DC current into a capacitor has been studied in the early DC CB designs [8] and [9], since it provides gradual and well defined recovery voltage which reduces occurrence of re-striking. $\mathrm{SF}_{6}$ breaker commutates DC current into a capacitor in [8], but it has low opening speed and requires another switch to insert capacitor after 10-20 ms of arcing when contacts achieve adequate separation distance. With air-blast breaker [9] an inductor is inserted in the commutating circuit to shape LC oscillation, and arcing of $10-20 \mathrm{~ms}$ is also present. The DC current commutation into a capacitor using semiconductor switches is also used in the recent DC CB [6].

Recent research in [13] proposes series LC DC CB which commutates 130 A current into a capacitor, but commutation is not analyzed and parasitic parameters are neglected.

The high-speed mechanical switches with Thomson coil actuators have been known for many years [14],[15], but only recently they have been developed to commercial products with very impressive operating speeds. The GIS $320 \mathrm{kV}$ disconnector operates in $2 \mathrm{~ms}$ [16] and has been employed in the DC CB in [4]. The vacuum disconnector of $40 \mathrm{kV}$ operates in $2 \mathrm{~ms}$ [17] and has been employed in DC CB in [5]. A similar $120 \mathrm{kV}$ disconnector is used in DC CB [6]. These fast disconnectors exclusively open at zero currents.

This research studies in depth DC current commutation into a capacitor. Fast disconnector switch with specific design features will be used. The aim is to reduce commutation time and to reduce or eliminate arcing. Analytical methods will develop theoretical basis for the commutation process, while non-linear simulation provides a more accurate model. The study is supported with substantial experimental results on a laboratory hardware of around 400-500 A DC current. 


\section{FAST DC CURRENT COMMUTATION INTO A CAPACITOR}

\section{A. Circuit description}

The circuit of interest is shown in Fig. 1, which resembles the study in [13]. Switch $S_{1}$ is of mechanical design (disconnector), which is initially closed and takes full current $i_{\text {dc }}$. The challenge is to understand the conditions for current commutation to capacitor when $S_{1}$ opens and in particular:

- Will dielectric breakdown and arcing across $\mathrm{S}_{1}$ contacts occur and for how long?

- What is the required switch topology?

- What magnitude of current $i_{\mathrm{dc}}$ can be commutated?

- What would be the required capacitance Cs?

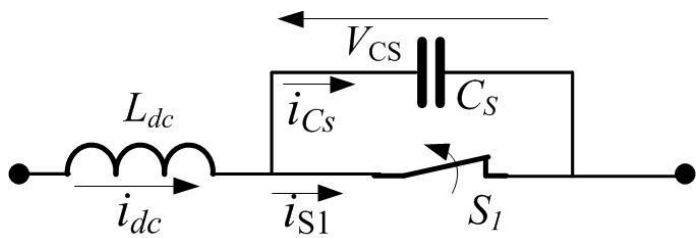

Fig. 1. DC current commutation circuit of interest.

\section{B. Theoretical conditions for ideal circuit}

It is assumed that the distance between electrodes of $S_{1}$ is $Z$ which is in the range $0<\mathrm{z}<\mathrm{Z}_{\max }$ while contacts are moving apart. $Z_{\max }$ is the maximal electrode gap which occurs at time $t_{\max }$. At any instant while contacts are moving apart, the contacts are capable of withstanding voltage $\mathrm{v}_{\mathrm{b}}$ which is assumed:

$v_{b}=z E_{b}, \quad 0<z<z_{\max }$

where $\mathrm{E}_{\mathrm{b}}$ is the dielectric strength of insulating medium, which for air is $\mathrm{E}_{\mathrm{b}_{-} \text {air }}=3 \mathrm{kV} / \mathrm{mm}$, while for $\mathrm{SF}_{6}$ it is $\mathrm{E}_{\mathrm{b}_{-} \mathrm{SF} 6}=7.5 \mathrm{kV} / \mathrm{mm}$ (at 1bar). Dielectric strength is assumed constant since no thermal phenomena are considered, although impact of contact geometry is neglected. In order to avoid breakdown, the following critical dielectric condition should be satisfied:

$$
z E_{b}>v_{c s}, \quad 0<z<z_{\max }
$$

where the capacitor voltage $\mathrm{v}_{\mathrm{Cs}}$ is assumed identical to the contact gap voltage (recovery voltage). In this section the circuit is assumed ideal, with no parasitic inductances.

It is also of interest to express derivative of contact distance:

$v=\frac{d z}{d t}, \quad 0<z<z_{\max }, \quad 0<t<t_{\max }$

where $\mathrm{v}$ is the contact velocity. The derivative of $\mathrm{v}_{\mathrm{Cs}}$ is:

$\frac{d v_{C s}}{d t}=\frac{i_{C s}}{C_{s}}, \quad 0<t<t_{\max }$

Replacing (3) and (4) into inequality (2):

$$
E_{b} \int_{0}^{t_{\max }} v d t>\int_{0}^{t_{\max }}\left(\frac{d v_{C s}}{d t}\right) d t, \quad 0<t<t_{\max }
$$

The above equation is valid for any final time $t_{\max }$ including the instant of contact separation (commutation) at $t=0$. Replacing $\mathrm{t}_{\max }=0$ in (5):

$$
v_{0} E_{b}>\frac{I_{0}}{C_{s}}, \quad z=0, t=0
$$

where $\mathrm{v}_{0}$ is the contact velocity at the separation instant and $\mathrm{I}_{0}$ is the current magnitude at the separation instant.

Equation (6), is valid for ideal conditions, and it is observed that the conditions to commutate non-zero current $I_{0}$ are [13]:

- Contacts have non-zero velocity at separation $\mathrm{v}_{0}$,

- There is a finite capacitance $\mathrm{C}_{\mathrm{s}}$ across contacts.

\section{Switch design}

The commutating switch employed in [8][9], [12] and many commercial switchgear cannot satisfy (6). They have butt contacts with springs facilitating adequate closed contact force. These switches have zero contact velocity at $\mathrm{z}=0$, and this results in very gradual contact gap increase in the initial period.

The condition of $v_{0}>0$ can be satisfied if switch $S_{1}$ has lateral contact overlap in closed state which is shown in a simplified diagram in Fig. 2. The disconnector in [14] and many conventional $\mathrm{SF}_{6}$ switches have similar construction. The lateral overlap of contacts in closed state is denoted as OL and enables contacts to accelerate to a non-zero velocity before separation. The contact separation distance $\mathrm{z}$ is determined using the contact positions $\mathrm{x}_{1}$ and $\mathrm{x}_{2}$, as shown in Fig. 2:

$$
z=x_{1}+x_{2}-O L
$$

A high-speed switch will be commonly driven by a pair of TCs (Thomson coil), as shown in Fig. 2, which provide fast acceleration. By knowing dynamics of switch contacts and the repulsive force of Thomson coils, the velocity of contacts can be determined [7], including crucial velocity at separation $\mathrm{v}_{0}$.

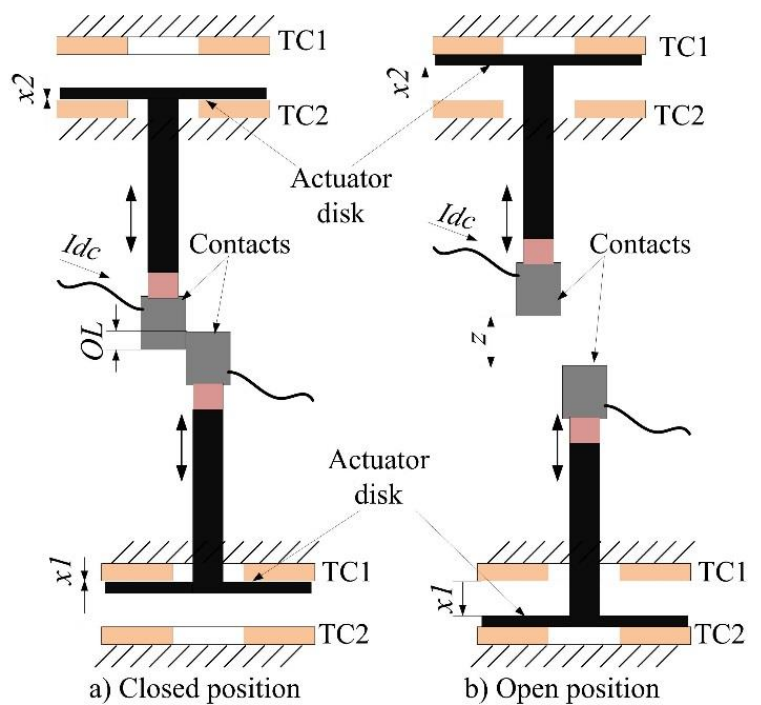

Fig. 2. Structure of a high-speed switch with lateral contact overlap. 


\section{Condition to avoid post-commutation re-strike}

The equation (1) should be satisfied in every instant of the contact stroke, and at the maximum distance it becomes:

$$
z_{\max } E_{b}>v_{C s \max }
$$

where the voltage $\mathrm{v}_{\mathrm{Csmax}}$ can be determined from the arrester voltage. The instant when maximum voltage occurs will be dependent on the capacitance and current using (8):

$z_{\max } E_{b}>\frac{1}{C_{s}} \int_{0}^{t_{\max }} i_{c s} d t, \quad 0<t<t_{\max }$

It is not intension of this article to analyze in depth the full trajectory of the contact movement and the capacitor current waveform. As the first approximation, an average current while contacts are moving $\mathrm{I}_{\mathrm{Csav}}$ can be used for initial dimensioning:

$$
z_{\max } E_{b}>\frac{I_{C s a v}}{C_{s}} t_{\max }
$$

\section{EXPERIMENTAL TESTING}

\section{A. Experimental circuit}

Fig. 3 shows the schematic of the complete test circuit and it gives the test circuit parameters.

The DC CB testing rig at the Aberdeen HVDC laboratory has been used previously for testing hybrid and mechanical DC $\mathrm{CBs}$, and it is described in [7] and [18]. It controls DC voltage to $0.9 \mathrm{kV}-1 \mathrm{kV}$, and supplies fault current of over $500 \mathrm{~A}$.

Fig. 4 shows the photograph of the commutating circuit $\left(\mathrm{S}_{1}\right.$, $\mathrm{L}_{\mathrm{dc}} \mathrm{Cs}$ and energy absorbers). The residual switch $\mathrm{S}_{2}$ is a commercial AC circuit breaker (Kilovac) which is used to interrupt LC oscillations after the commutation. The capacitor bank is purposely located close to the commutating switch to reduce parasitic inductance.

Fig. 5 shows the fast disconnector $S_{1}$ separately. The highspeed disconnector operates in around $1-2 \mathrm{~ms}$ with $3 \mathrm{~mm}$ separation in air, and it is described in [19]. A theoretical $\mathrm{E}_{\mathrm{b}}=3 \mathrm{kV} / \mathrm{mm}$ may not be valid because of contact geometry and some bounce, and therefore a conservative peak stress of 1.2$1.5 \mathrm{kV}$ is applied. Copper contacts of $20 \mathrm{~mm}$ width are used, while the closed-state overlap is $\mathrm{OL}=1.5 \mathrm{~mm}$. Thomson coils are described in [19], and they have adjustable driver voltage which enables changes in the contact speed and opening time.

Fig. 6 shows the capacitor bank $\mathrm{C}_{\mathrm{s}}$ (with four capacitors) and the energy absorbers. Bus bars are used to reduce inductance.

The measurements of variables are achieved as:

- The contact position $\mathrm{x}$ is measured using hall-effect sensors [19]. Contact separation $\mathrm{z}$ is estimated using (7) . Contact velocity is calculated by differentiating $\mathrm{z}$.

- Currents $i_{\mathrm{dc}}$ and $i_{\mathrm{s} 1}$ are measured using identical Agilent, $2 \mathrm{MHz}, 500 \mathrm{~A}$ DC probes. It is not possible to measure $\mathrm{i}_{\mathrm{Cs}}$ because of close location of capacitors. Arrester current $i_{S A}$ is measured using a standard AC probe.

- Voltages are measured using TESTEC, $100 \mathrm{MHz}$, differential probes.
- Data is captured at 2000 points on Agilent $200 \mathrm{MHz}$ oscilloscope. The time is synchronized with $\mathrm{S}_{1}$ trigger.

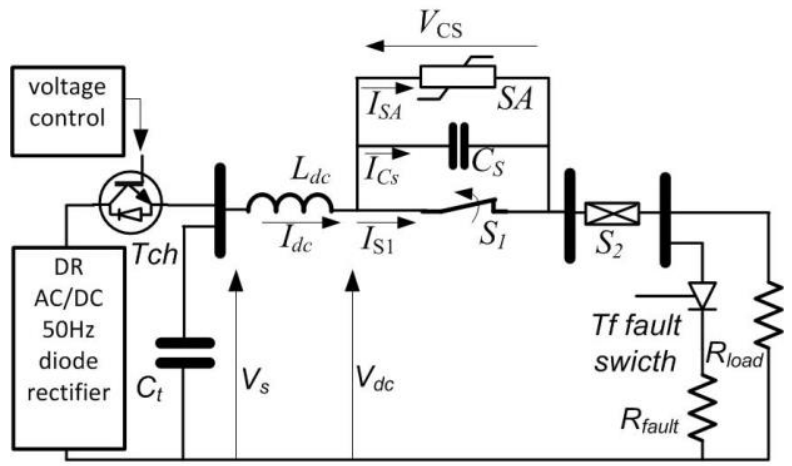

$D R$ - Diode rectifier (1170V, 30A)

$T_{\text {ch }}$ - Chopper IGBT, (1700V, 300A),

$T_{f}$ - Fault thyristor, (1800V, 273A),

$\mathrm{C}_{t}$ - Storage Capacitor, $(7080 \mu \mathrm{F}, 1200 \mathrm{~V})$,

$L_{d c}$ - Series inductor, $(0.0038 \mathrm{H})$,

$R_{\text {load }}$ - Load Resistor, (99 $\Omega$ ),

$R_{\text {fault }}-$ Fault Resistor, $(0.4 \Omega)$,

SA - Surge arrester (1200V, TDK 2xB60K275)

$\mathrm{S}_{2}$ - Residual switch (AC CB, Kilovac EV200HAANA)

$S_{1}$ - Fast disconnector,

$\mathrm{C}_{\mathrm{s}}$ - Commutating capacitor

Fig. 3. Experimental test circuit.

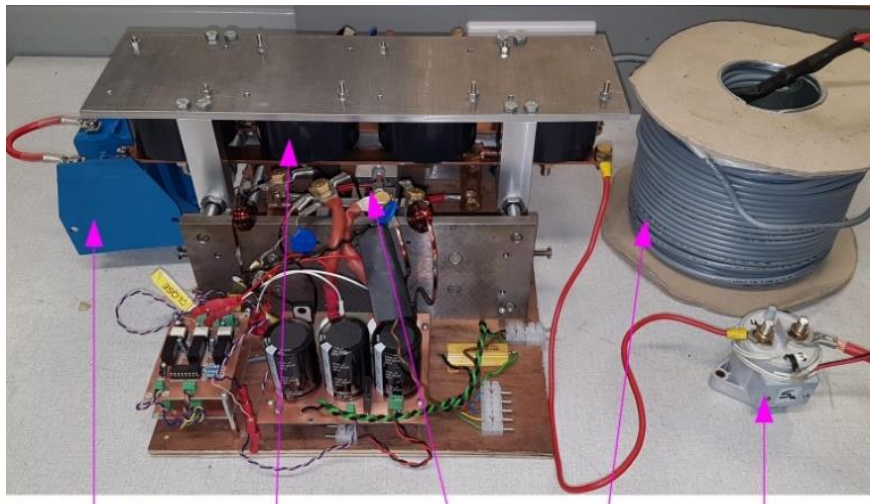

Arresters SA Capacitors Cs Contacts S1 Inductor Ldc Residual switch S2 Fig. 4. Photograph of the experimental test circuit.

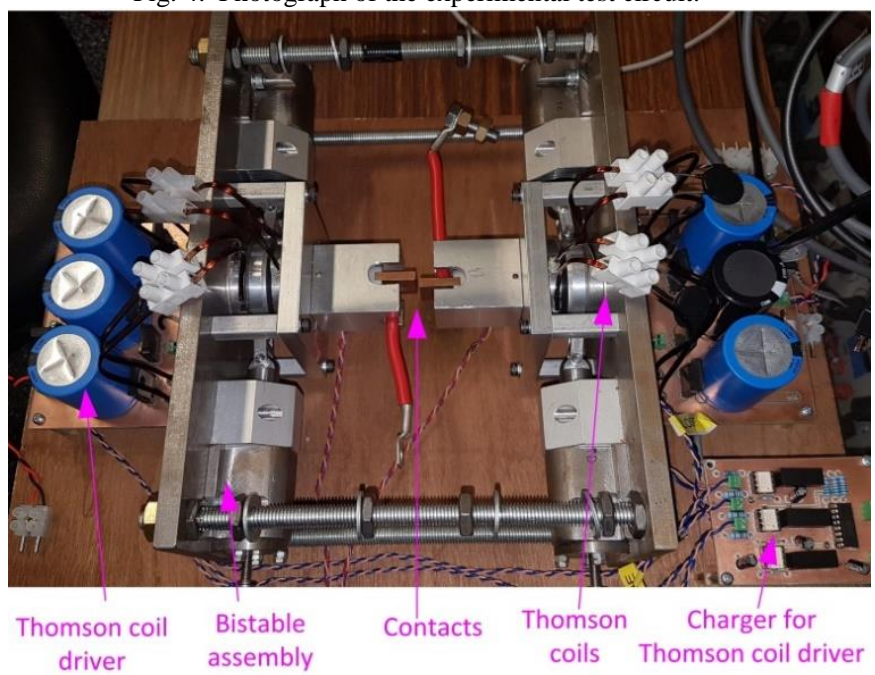

Fig. 5. Fast disconnector $S_{1}$. 


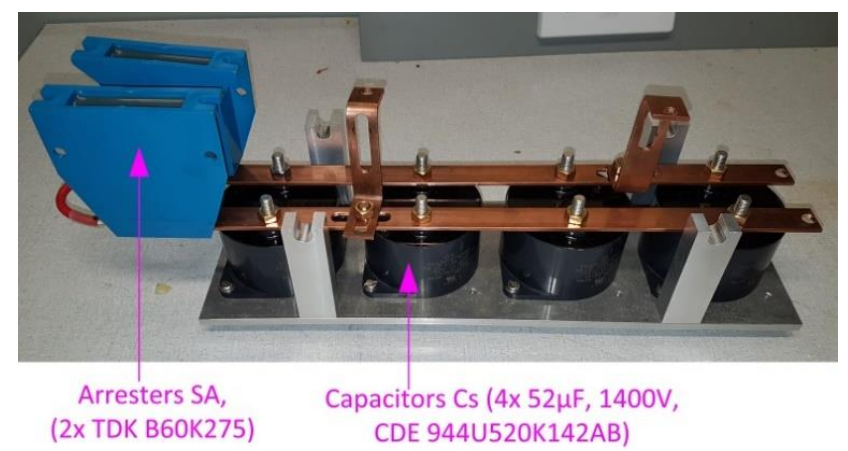

Fig. 6. Commutating capacitor $C s$ and arrester SA.

\section{B. Experimental results}

The first goal was to evaluate validity of equation (6). The following test plain is adopted:

1. For a fixed capacitance $\mathrm{C}_{\mathrm{s}}$ and commutating current $\mathrm{I}_{0}$ the responses are observed/recorded when $S_{1}$ opens. Note is taken if commutation is successful or if it fails.

2. Current $\mathrm{I}_{0}$ is increased in a small step and test repeated. Current is further increased until commutation fails. This enables testing the impact of commutating current.

3. Capacitance is increased and steps 1-2 repeated.

A $52 \mu \mathrm{F}, 1400 \mathrm{~V}$ capacitor is used as the basic unit and four test sets are performed with $52 \mu \mathrm{F}, 104 \mu \mathrm{F}, 156 \mu \mathrm{F}$ and $208 \mu \mathrm{F}$ (Fig. 6 shows all four capacitors in the circuit).

Fig. 7 shows commutation of 400A DC current, using $208 \mu \mathrm{F}$ capacitance. It is seen that $400 \mathrm{~A}$ current is transferred from the switch to the capacitor practically instantaneously. Voltage across switch raises to $1.3 \mathrm{kV}$ in around $1 \mathrm{~ms}$ and no arcing is observed. Voltage magnitude is limited by arresters. It is seen that commutation occurs around $350 \mu \mathrm{s}$ after the trip signal. Contacts are sliding for $350 \mu$ s (including a dead-time of 50$100 \mu$ s before they begin to move) while conducting current.

Fig. 8 shows the contact position measurements which is same for all tests. The distance between contacts $\mathrm{z}$ is calculated using measured position of each rod (shown as $\mathrm{x}_{1}$ and $\mathrm{x}_{2}$ ) and calibrated to indicate separation at the instant of voltage increase. It is seen that sepration occurs at around $350 \mu$ s and that gap velocity at separation is $\mathrm{v}_{0}=2.5 \mathrm{~m} / \mathrm{s}$.

Fig. 9 shows the summary of measurements for different capacitances. The failed commutation is marked with " $x$ " which always occurs at somewhat larger current than the last successful commutation. Many tests have been performed with different capacitances and different currents. The results have been reliable and largely predictable. Experience shows that tests are repeatable with only a very small uncertainty (it fails for the same or very similar current magnitude for repeated tests). No re-striking is observed or stochastic phenomena.

Each time the failure occurs, a substantial arc for around 3-4 $\mathrm{ms}$ is observed and substantial contact damage occurs. Replacement of contacts has been necessary after each failure.

The curves "ideal model" in Fig. 9 is obtained using (6). It is seen that these curve are overly optimistic in predicting the maximum commutating current for the given parameters.
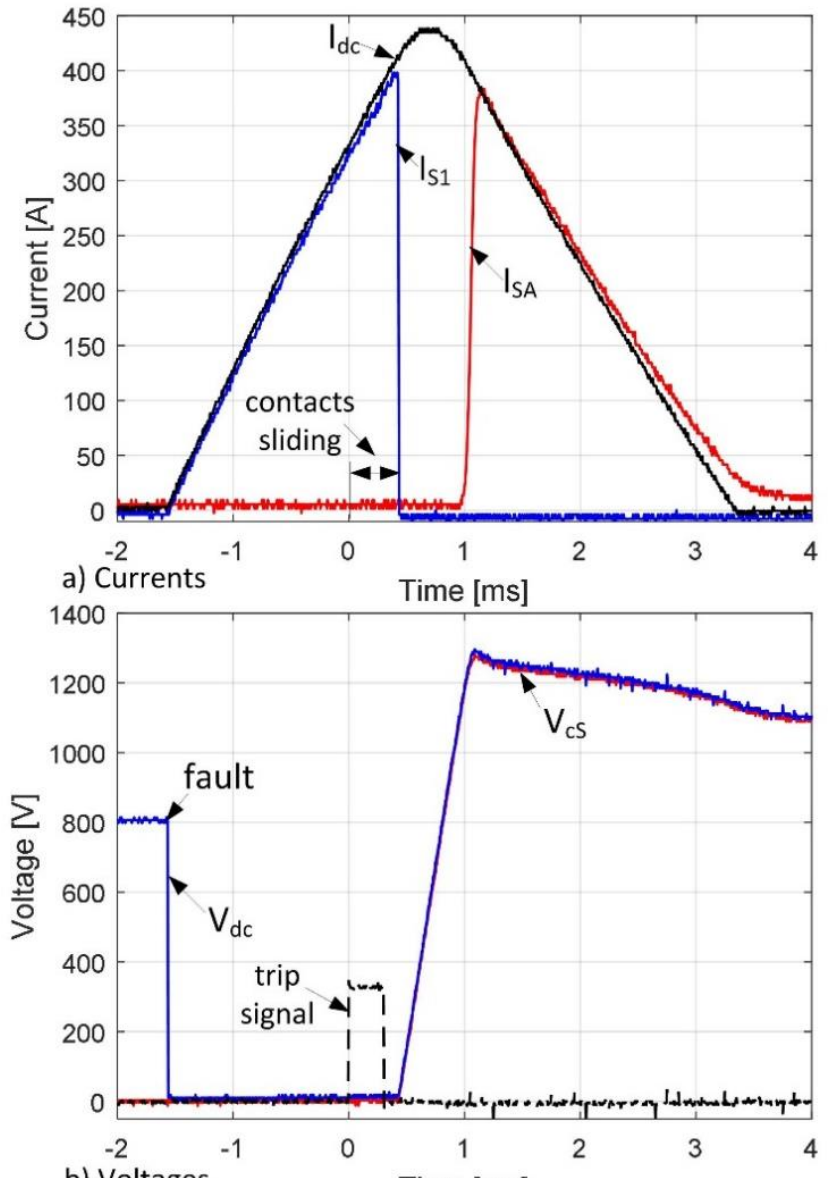

b) Voltages

Time [ms]

Fig. 7. Experimental measurement of $400 \mathrm{~A}$ commutation $(C s=208 \mu \mathrm{F})$.

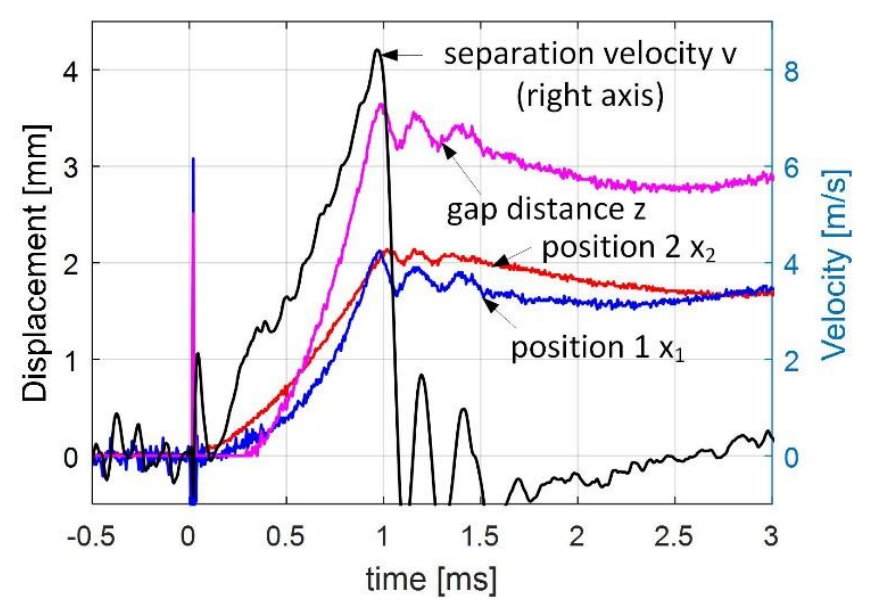

Fig. 8. Contact position, gap distance and velocity.

It is suspected that the commutation fails at lower-thanexpected currents because of parasitic inductance and resistance in the commutating circuit. This can be confirmed by observing responses for failed commutation at $430 \mathrm{~A}$ with $208 \mu \mathrm{F}$, which are shown in Fig. 10. The switch current $i_{\$ 1}$ reduces rapidly but it fails to reach zero and continues to oscillate. The damped oscillations are of high frequency (over $20 \mathrm{kHz}$ ) and are caused by parasitics in the commutating circuit. 


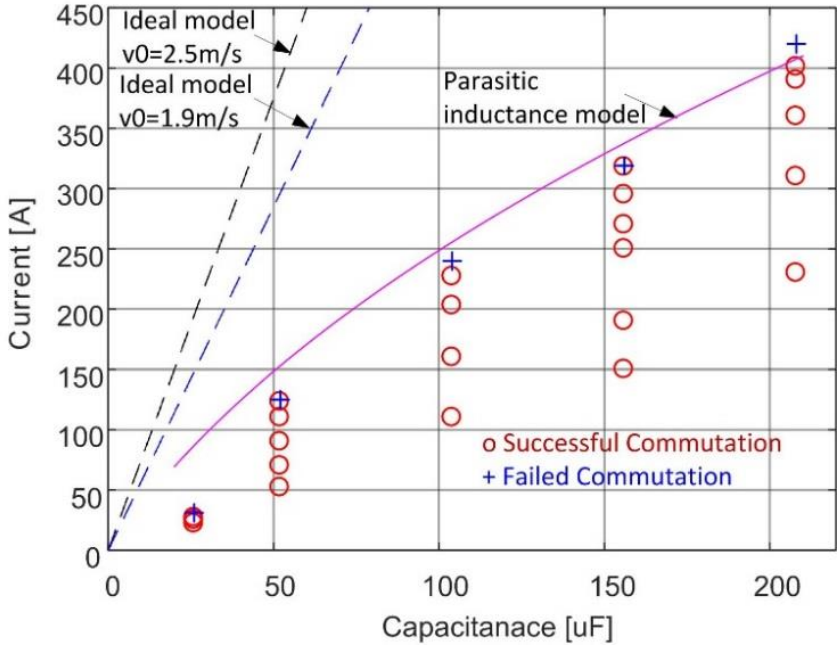

Fig. 9. Experimental measurements for different capacitances.

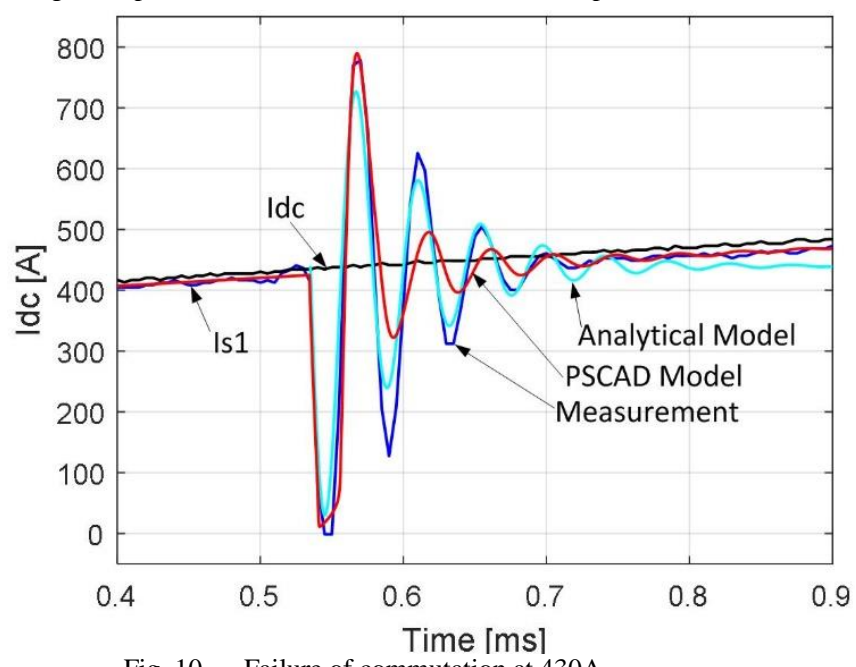

Fig. 10. Failure of commutation at 430A.

Fig. 10 also helps understanding the commutation process. The commutation is successful if the first peak of the parasitic oscillating current falls below zero, since this interrupts arc current. Therefore the gap medium conducts current (arcing time) only for the first $1 / 4$ of the parasitic oscillation. In the demonstrated successful commutation tests the arcing lasts for around 5-10 $\mu \mathrm{s}$. This is 3 orders of magnitude shorter than arcing in the commercial mechanical DC CBs in [8]- [10]. Since arcing period is so short, minimal energy is dissipated and thermal phenomena are not important for the analysis (dielectric phenomena are crucial). The arcing of several $\mu$ s is practically unmeasurable [12] and is not likely to cause any contact wearing. It is therefore believed that common disconnectors would be suitable switches for this commutation method. In practical terms, since arcing is so short, contacts can be lighter, and may operate at higher speeds.

\section{A. Tests with different contact velocity}

Contact velocity at separation instant $\mathrm{v}_{0}$ is the key parameter in this design as it is seen in (6). Beside the illustrated tests with $\mathrm{v}_{0}=2.5 \mathrm{~m} / \mathrm{s}$ (opening in $1 \mathrm{~ms}$ ) further tests were also performed with lower speed of $\mathrm{v}_{0}=1.9 \mathrm{~m} / \mathrm{s}$ (opening in $2 \mathrm{~ms}$ ). At lower speed the "ideal model" curve has lower slope as shown in Fig. 9 , but it is still above the current limits caused by parasitics, and therefore similar results are obtained. As it will be illustrated below, contact velocity has no influence on the parasitic circuit.

\section{B. Arc voltage tests without capacitor $C s$}

The study in [12] concludes that the comparison of arc voltage and the voltage across parasitic elements determines success of DC current commutation. In order to measure te arc voltage, the commuating capacitor is removed from the circuit and measuremennts are taken at various current levels. Without capacitor, the arc voltage is more stable and enables understanding the electrode fall (intial arc voltage).

The measurements of arc voltage at 2 different currents ( $2 \mathrm{~A}$ and $180 \mathrm{~A}$ ) are shown in Fig. 11. It is seen that this switch is unable to interrupt $1.3 \mathrm{~A} \mathrm{DC}$ current without DC capacitor. It is also observed that the DC current drops from $2 \mathrm{~A}$ to $1.3 \mathrm{~A}$ while contacts are sliding, because of marginally increased resistance. This is the consequence of slight increase in contact resistance while contacts are sliding, however such drop is not noticable at higher currents. At low currents the electrode fall is larg (20$30 \mathrm{~V}$ ) which explains the negative resistance slope and is consistent with measurements in [20].

In Fig. 11b) for $180 \mathrm{~A}$ current, and in general for all currents over $20 \mathrm{~A}$, the arc voltage is around $15-18 \mathrm{~V}$ at separtion $\mathrm{z}=0$. The arc voltage then slightly increases as gap distance incrases. These measuremest are in general agreement with results from [12] and [20].
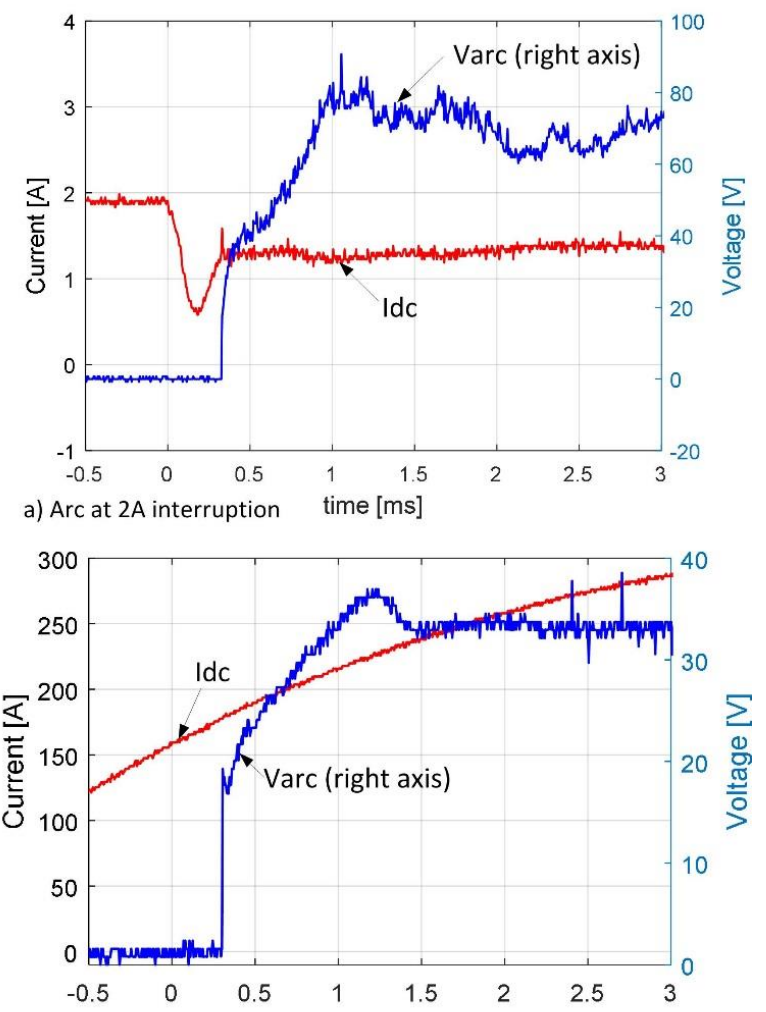

b) Arc at $180 \mathrm{~A}$ interruption time [ms]

Fig. 11. Arc voltage experimental measurements.

\section{MODEL OF PARASITIC CIRCUIT}

\section{A. Non-linear model in PSCAD}

A detailed circuit model including parasitics is developed in PSCAD, and Fig. 12 shows just the model of the commutating 
circuit. PSCAD has a only a simple switch model, and the arcing switch is represented with two switches $\left(\mathrm{S}_{1 \mathrm{a}}\right.$ and $\left.\mathrm{S}_{1 \mathrm{~b}}\right)$ and a non-linear resistor $\mathrm{R}_{\text {arc. }}$. Both switches are commanded to open on the trip signal, however they respond differently:

- $\mathrm{S}_{1 \mathrm{a}}$ is an ideal switch capable of opening only at zero current, which provides isolation when arc current reduces to zero.

- $\mathrm{S}_{\mathrm{lb}}$ is an ideal switch capable of opening at any current, which will interrupt current immediately and insert $R_{\text {arc }}$.

Once $S_{1 b}$ opens, current is falls, and if it reduces to zero $S_{1 a}$ opens and commutation is successful.

The value for $R_{\text {arc }}$ is adjusted to match the experimental results as shown in Table I. Non-linear $R_{\text {arc }}$ enables accurate representation of the arc voltage dependency on the current.

$\mathrm{L}_{\mathrm{p} 1}$ represents capacitor parasitic inductance, while $\mathrm{L}_{\mathrm{p} 2}$ represents the copper bus bar inductance. $R_{p 1}$ is the capacitor series resistance. At each topology (with different capacitance) the period and damping of the parasitic oscillating circuit are calculated using measurements of the oscillating response for the failed case (as in Fig. 10). Then, curve fitting is used to estimate the values for $\mathrm{L}_{\mathrm{p} 1}$ and $\mathrm{L}_{\mathrm{p} 2}$, as shown in Fig. 13. The period of parasitic oscillations is also shown in Fig. 13, and can be used for estimation of the arcing duration (1/4 of the period).

The parameters of this model are shown in Table II. The testing of this model against experimental results is shown in Fig. 10, and it is seen that model accuracy is good.

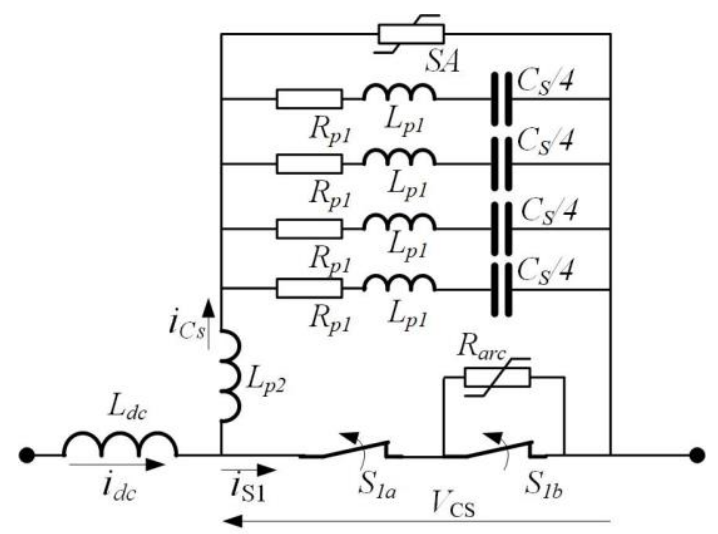

Fig. 12. Commutating circuit model in PSCAD.

Table I Arc resistance in the PSCAD model.

\begin{tabular}{|c|c|c|c|c|}
\hline \hline Current & Resistance & & Current & Resistance \\
\hline \hline $0.5 \mathrm{~A}$ & $50 \Omega$ & & $200 \mathrm{~A}$ & $0.08 \Omega$ \\
\hline \hline $1 \mathrm{~A}$ & $100 \Omega$ & & $300 \mathrm{~A}$ & $0.053 \Omega$ \\
\hline \hline $2 \mathrm{~A}$ & $25 \Omega$ & & $500 \mathrm{~A}$ & $0.035 \Omega$ \\
\hline \hline $10 \mathrm{~A}$ & $16 \Omega$ & & $600 \mathrm{~A}$ & $0.033 \Omega 0$ \\
\hline \hline $100 \mathrm{~A}$ & $0.16 \Omega$ & & $10000 \mathrm{~A}$ & $0.002 \Omega$ \\
\hline \hline
\end{tabular}

Table II Parameters of the commutating circuit model.

\begin{tabular}{||c|c||c|c|}
\hline \hline \multicolumn{2}{|c||}{ PSCAD model } & \multicolumn{2}{c|}{ Analytical model } \\
\hline \hline Rp1 & $0.03 \Omega$ & $R p$ & $\mathrm{R}_{\mathrm{p} 1} /\left(\mathrm{C}_{\mathrm{s}} / 52 \mu \mathrm{F}\right)$ \\
\hline \hline Lp1 & $130 \mathrm{nH}$ & $\mathrm{Lp}$ & $\mathrm{L}_{\mathrm{p} 1}+\mathrm{L}_{\mathrm{p} 2} /\left(\mathrm{C}_{\mathrm{s}} / 52 \mu \mathrm{F}\right)$ \\
\hline \hline Lp2 & $195 \mathrm{nH}$ & $\operatorname{Varc0}$ & $16 \mathrm{~V}$ \\
\hline
\end{tabular}

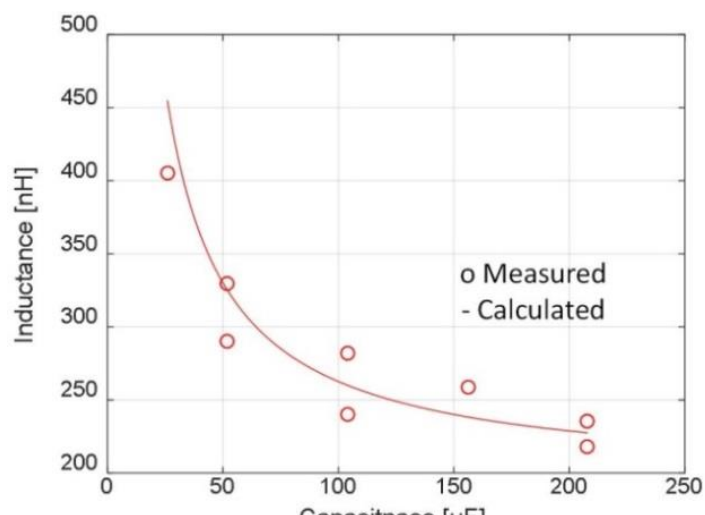

a) Parasitic inductance Capacitnace [uF]

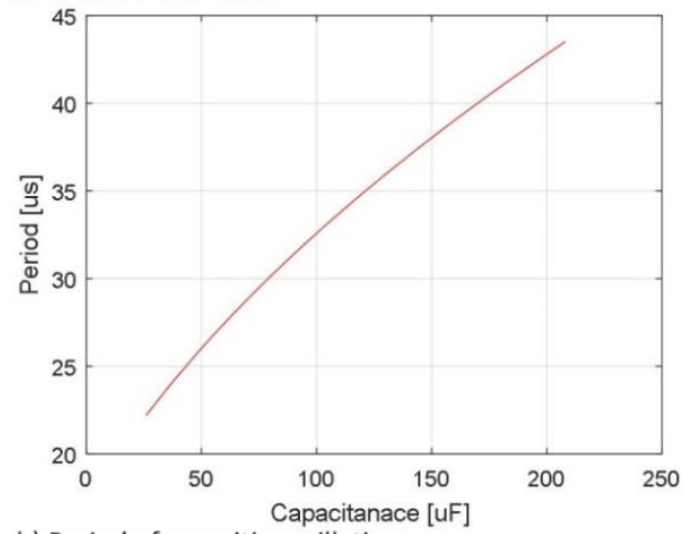

b) Period of parasitic oscillation

Fig. 13. Estimation of parasitic inductances and the period.

\section{B. Analytical model}

The analytical modeling of DC current commutation through parasitic circuit is well described in [12]. Similar approach is used here but capacitor is included in the circuit as shown in Fig. 14. This model enables fast parametric studies. Instead of non-linear resistance, in this linear model a simple constant voltage $\mathrm{V}_{\text {arc } 0}=16 \mathrm{~V}$ is used to represent arc. This is justified since gap distance changes only marginally (around $40 \mu \mathrm{m}$ ) for the short arcing duration, and has no noticeable impact on the arc voltage. A single $\mathrm{Lp}$ is used for simplicity.

Using circuit theory, the time domain expression for the current is $1_{1}$ after $S_{1}$ opens, can be derived as:

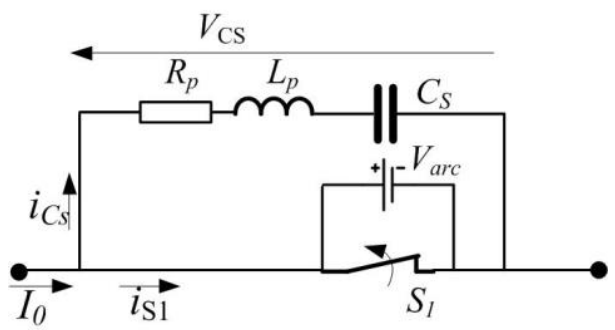

Fig. 14. Analytical model of commutating circuit.

$i_{S 1}=I_{0}-\frac{V_{a r c 0}}{z_{p} \sqrt{1-\zeta^{2}}} \mathrm{e}^{-\zeta \omega_{p d} t} \sin \left(\omega_{p d} t\right)$,

where subscript 0 denotes values at commutation, and: 


$$
\begin{aligned}
& \omega_{p d}=\omega_{p} \sqrt{1-\zeta^{2}}, \quad \omega_{p}=1 / \sqrt{L_{p} C_{s}}, \\
& \zeta=R_{p} /\left(2 Z_{p}\right), \quad Z_{p}=\sqrt{L_{p} / C_{s}},
\end{aligned}
$$

The value of the first peak of the oscillating current in (11) is:

$$
I_{P 1}=\frac{V_{\operatorname{arc} 0}}{e^{\frac{\pi R_{p}}{4} \sqrt{\frac{C_{s}}{L_{p}}}} \sqrt{\frac{L_{p}}{C_{s}}-\left(\frac{R_{p}}{2}\right)^{2}}}
$$

If this peak current $\mathrm{I}_{\mathrm{p} 1}$ is larger than $\mathrm{I}_{0}$ then current crosses zero and commutation is successful. The parameters of this model are shown in Table II.

The accuracy of this model has been confirmed by testing against experimental results is shown in Fig. 10. Equation (13) is also verified for other values of capacitance and the curve is shown as "Parasitic inductance model" in Fig. 9. It is seen that this model quite accurately predicts maximum current that can be commutated. Because of arc voltage increase for low currents, this model is inaccurate for $\mathrm{I}_{0}<20 \mathrm{~A}$.

Therefore, the ideal model in (6) gives only necessary condition. The commutation is successful if both: ideal and parasitic model conditions are satisfied.

\section{Commutating higher DC current and practical design}

Of primary practical importance for a possible DC CB design is the magnitude of the DC current that can be commutated. Considering (13), DC current magnitude can be increased by:

- Increasing $\mathrm{C}_{\mathrm{s}}$,

- Increasing $\mathrm{V}_{\operatorname{arc} 0 \text {, }}$

- Reducing $\mathrm{L}_{\mathrm{p}}$,

- Reducing $\mathrm{R}_{\mathrm{p}}$.

The arc voltage can be increased in various ways like using different medium, contact geometry or using multiple break points. The benefit of two breaking points is in doubling the arc voltage, as it has been experimentally confirmed in [9]. Fig. 15 shows the required arc voltage to commutate larger currents for a range of parasitic inductances, and capacitances (the base case is $\mathrm{C}_{\mathrm{s}}=208 \mu \mathrm{F}, \mathrm{L}_{\mathrm{p}}=233 \mathrm{nH}, \mathrm{R}_{\mathrm{p}}=0.0092 \Omega, \mathrm{V}_{\mathrm{arc}}=16 \mathrm{~V}$ ). As an example, with approximately 4 break points it might be possible to commutate around $2000 \mathrm{~A}$ on this test circuit assuming all other parameters are unchanged.

The methods for reducing parasitic inductances also exist, like for example sandwich bus bar commonly used with Voltage Source Converters.

Considering (6), higher current can be commutated by:

- Increasing velocity at separation $\mathrm{v}_{0}$,

- Increasing capacitance $\mathrm{C}_{\mathrm{s}}$,

- Increasing dielectric strength $\mathrm{E}_{\mathrm{b}}$.
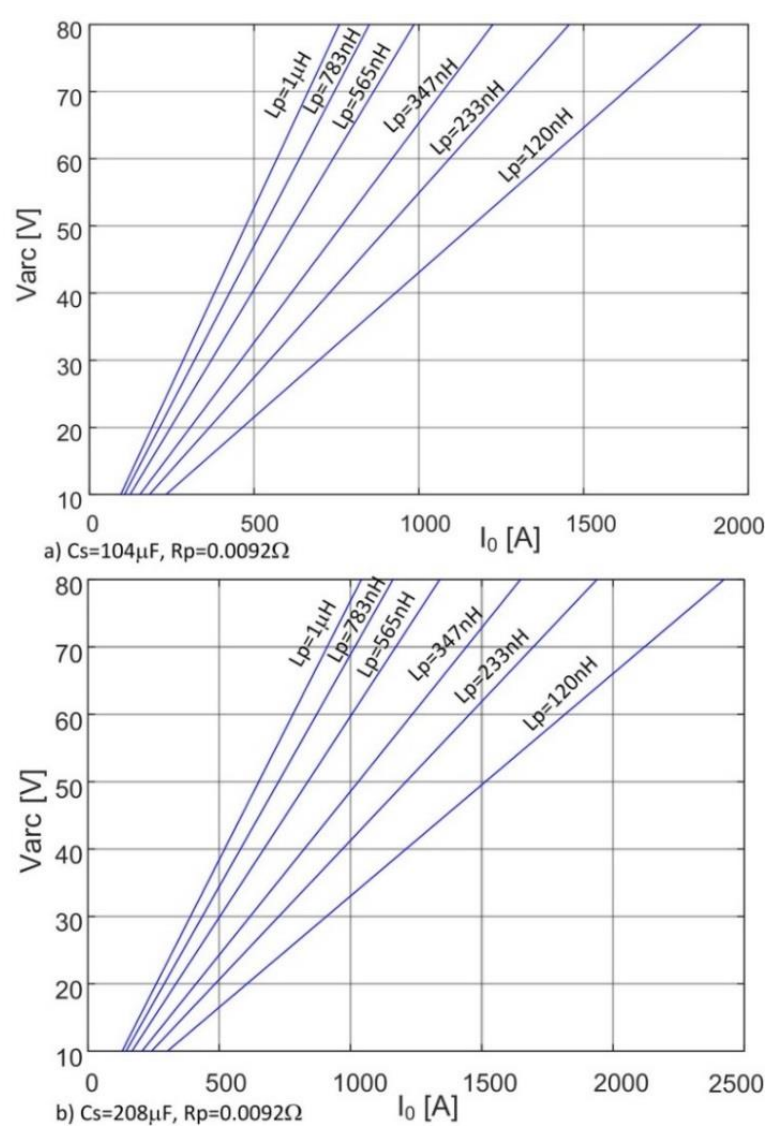

Fig. 15. Arc voltage versus commutating current.

\section{SCALING FOR HIGH VOLTAGES AND CURRENTS}

No tests have been performed at higher currents/voltages or cost evaluations for scaling to transmission-level voltages. However it might be of benefit to evaluate some key parameters for a transmission-level case using the developed models.

Table III shows the basic parameters for practical $320 \mathrm{kV} \mathrm{SF}_{6}$ disconnector from [14], and the calculated capacitance according to (6), with presumed $4 \mathrm{kA}$ commutating current. The obtained value for capacitance is $14.5 \mu \mathrm{F}$ which is acceptable.

The parasitic parameters are very difficult to evaluate, and [12] recommends inductance of $200 \mathrm{nH} / \mathrm{m}$ while resistance is $10 \mu \Omega / \mathrm{m}$ for bus bars. Parasitic inductance for the capacitors should be added. Fig. 16 shows the required arc voltage versus commutating current, assuming a more conservative capacitance of $50 \mu \mathrm{F}$. It shows that with $\mathrm{L}_{\mathrm{p}}=5 \mu \mathrm{H}$ the arc voltage of $1.1 \mathrm{kV}$ could commutate current of $4 \mathrm{kA}$.

Table III Estimated parameters for $320 \mathrm{kV}, 4 \mathrm{kA}$ commutation.
\begin{tabular}{|l|l|l|l|l|}
\hline $\begin{array}{l}\text { Peak } \\
\text { voltage }\end{array}$ & $\begin{array}{l}\text { Contact } \\
\text { distance }\end{array}$ & $\begin{array}{l}\text { Contact } \\
\text { velocity v }\end{array}$ & $\begin{array}{l}\text { Current } \\
\mathrm{I}_{0}\end{array}$ & $\begin{array}{l}\text { Capacitance } \\
\mathrm{C}_{\mathrm{s}}\end{array}$ \\
\hline $550 \mathrm{kV}$ & $0.073 \mathrm{~m}$ & $37 \mathrm{~m} / \mathrm{s}$ & $4000 \mathrm{~A}$ & $14.5 \mu \mathrm{F}$ \\
\hline
\end{tabular}






Fig. 16. Arc voltage versus commutating current for $\mathrm{HV}$ application.

\section{CONCLUSION}

The article describes a method of fast commutation of DC current into a capacitor. Theoretical study concludes that nonzero contact velocity at separation is required, and a particular switch design is proposed to meet this requirement. A simple equation enables evaluation of commutating current for the given contact velocity, capacitance and dielectric strength.

Experimental results on a laboratory set up illustrate successful DC current commutation up to $400 \mathrm{~A}$, with voltages of $1.3 \mathrm{kV}$. It is concluded that parasitic parameters reduce the magnitude of the current that can be commutated, and both: ideal and parasitic model conditions should be satisfied.

A detailed non-linear PSCAD model and linear model for the parasitic circuit are presented and evaluated. It is confirmed that the models enable accurate prediction of the commutation.

The DC current commutation in the proposed method occurs 5-10 $\mu \mathrm{s}$ after the contact separation, which is much faster than with other methods with moving contacts. In practical terms, this method has no arcing which eliminates thermal issues and simplifies mechanical design of the switch.

\section{ACKNOWLEDGMENT}

The author is thankful to Mr R. Osborne from University of Aberdeen for help with the experimental studies.

\section{REFERENCES}

[1] D Jovcic "High Voltage Direct Current Transmission: Converters Systems and DC Grids", second edition, Wiley, 2019.

[2] CIGRE joined WG A3 and B4.34 "Technical Requirements and Specifications of State of the art HVDC Switching Equipment" CIGRE brochure 683, April 2017.

[3] C. M. Franck, "HVDC circuit breakers: A review identifying future research needs," IEEE Transactions on Power Delivery, Vol. 26, No. 2, pp. 998- 1007, April 2011.

[4] Häfner, J., Jacobson, B.: 'Proactive Hybrid HVDC Breakers - A key innovation for reliable HVDC grids'. Proc. CIGRE 2011 Bologna Symp., Bologna, Italy, Sep 2012, pp. 1-7.

[5] G.F. Tang, X. G. Wei, W.D. Zhou, S. Zhang, C. Gao, Z.Y. He, J. C. Zheng "Research and Development of a Full-bridge Cascaded Hybrid HVDC Breaker for VSC-HVDC Applications" A3-117 CIGRE Paris 2016.

[6] W. Grieshaber, J. Dupraz, D. Penache, et al., "Development and Test of a $120 \mathrm{kV}$ direct current circuit breaker," Proc. CIGRÉ Session, Paris, France, Aug 2014, pp. 1-11
[7] M Hedayati and D. Jovcic "Scaled 500A, 900V, Hardware Model Demonstartor of Mechanical DC CB with Current Injection" IEEE ISGT, Sarajevo, October 2018, pp 1-8.

[8] A. Lee, P. G. Slade, K. H. Yoon, J. Porter and J. Vithayathil, "The Development of a HVDC SF6 Breaker," in IEEE Transactions on Power Apparatus and Systems, vol. PAS-104, no. 10, pp. 2721-2729, Oct. 1985.

[9] B. Bachmann, G. Mauthe, E. Ruoss, H. P. Lips, J. Porter and J. Vithayathil, "Development of a 500kV Airblast HVDC Circuit Breaker," in IEEE Transactions on Power Apparatus and Systems, vol. PAS-104, no. 9, pp. 2460-2466, Sept. 1985.

[10] K. Tahata, S. Oukaili, K. Kamei, et al., "HVDC circuit breakers for HVDC grid applications," Proc. IET ACDC 2015 conference, Birmingham, UK, Feb 2015. pp. 1-9.

[11] C. Peng, A. Q. Huang and X. Song, "Current commutation in a medium voltage hybrid DC circuit breaker using $15 \mathrm{kV}$ vacuum switch and $\mathrm{SiC}$ devices," 2015 IEEE Applied Power Electronics Conference and Exposition (APEC), Charlotte, NC, 2015, pp. 2244-2250

[12] A. Ritter and C. M. Franck, "Prediction of Bus-Transfer Switching in Future HVdc Substations," IEEE Trans. on Power Delivery, vol. 33, no. 3, pp. 1388-1397, June 2018.

[13] D Jovcic "Series LC DC Circuit Breaker" IET High Voltage, 2019, DOI: $10.1049 /$ hve.2019.0003.

[14] R. Rajotte and M. G. Drouet, "Experimental analysis of a fast acting circuit breaker mechanism: Electrical aspects," IEEE Trans. Power App. Syst., vol. PAS-94, no. 1, pp. 89-96, Jan. 1975.

[15] T. Genji, O. Nakamura, M. Isozaki, M. Yamada, T. Morita, and M. Kaneda, "400 V class high-speed current limiting circuit breaker for electric power system," IEEE Trans. Power Del., vol. 9, no. 3, pp. 1428 1435, Jul. 1994.

[16] P. Skarby and U. Steiger, "An Ultra-fast Disconnecting Switch for a Hybrid HVDC Breaker- a technical breakthrough", Proc. CIGRÉ Session, Alberta, Canada, Sep 2013, pp. 1-9.

[17] W. Wen at all, "Research on Operating Mechanism for Ultra-Fast 40.5kV Vacuum Switches" IEEE Trans. on Power Delivery, Vol 30, no 6, pp 2553-2560, Dec 2015,

[18] M Hedayati and D. Jovcic "Reducing peak current and energy dissipation in hybrid HVDC CBs using Disconnector voltage control" IEEE Transactions on Power Delivery, Vol 33, iss 4, pp 2030-38, August 2018.

[19] M. Hedayati, D. Jovcic "Low Voltage Prototype Design, Fabrication and Testing of Ultra-Fast Disconnector (UFD) for Hybrid DCCB" CIGRE B4 colloquium, Winnipeg October 2017, pp 1-8.

[20] R. F. Ammerman, T. Gammon, P. K. Sen and J. P. Nelson, "DC-Arc Models and Incident-Energy Calculations," in IEEE Transactions on Industry Applications, vol. 46, no. 5, pp. 1810-1819, Sept.-Oct. 2010.

\section{BIOGRAPHY}

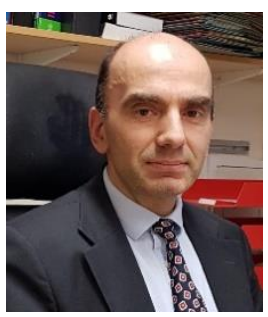

Dragan Jovcic (S'97-M'00-SM'06) obtained a Diploma Engineer degree in Control Engineering from the University of Belgrade, Serbia in 1993 and a $\mathrm{Ph} . \mathrm{D}$. degree in Electrical Engineering from the University of Auckland, New Zealand in 1999. He is currently a professor with the University of Aberdeen, Scotland where he has been since 2004. In 2008 he held visiting professor post at McGill University, Montreal, Canada. He also worked as a lecturer with University of Ulster, in the period 20002004 and as a design Engineer in the New Zealand power industry, Wellington, in the period 1999-2000. His research interests lie in the HVDC, FACTS, dc grids and control systems. 